\title{
"Comparative Estimation Of Salivary Aspartate Aminotransferase Levels In Patients With Varying Periodontal Conditions - A Clinico - Chemical Study".
}

\author{
Bhagyashri N. Vanaki ${ }^{1,}$ Sudhir R. Patil ${ }^{2,}$ Praveen S. Anigol ${ }^{3,}$ Nagaraj B. \\ Kalburgi ${ }^{1,}$ Narayan R. Vanaki ${ }^{4}$ \\ ${ }^{I}$ Department of Periodontics, PMNM Dental College \& Hospital Bagalkot, Karnataka, India. \\ ${ }^{2}$ Department of Periodontics, KLE Dental College \& Hospital Bangalore, Karnataka, India. \\ ${ }^{3}$ Department of Oral Pathology, PMNM Dental College \& Hospital Bagalkot, Karnataka, India. \\ ${ }^{4}$ Department of Psychiatry, S. N. Medical College and Hospital Bagalkot, Karnataka, India.
}

\begin{abstract}
Absrtact:Saliva is a fluid that can be easily collected, contains locally-derived and systemically-derived markers of periodontal disease, and hence may offer the basis for a patient specific diagnostic test for periodontitis. The present study evaluates the salivary levels of aspartate aminotransferase in periodontal disease conditions like gingivitis, periodontitis and their comparison with the healthy, based on their largest Community periodontal index of treatment needs code. Total of 100 participants were included. Twenty five patients in each group, assigned to four groups $\mathrm{CO}, \mathrm{Cl}, \mathrm{C} 3$ and $\mathrm{C} 4$. Mean levels of aspartate aminotransferase $(\mathrm{U} / \mathrm{ml})$ for groups $\mathrm{CO}-25.75, \mathrm{Cl}-30.59, \mathrm{C3}-46.90$ and $\mathrm{C4}-100.28$ and there were statistically significant differences ( $p<0.05$ ) between levels from group $\mathrm{CO}$ to $\mathrm{Cl}, \mathrm{C3}$ and $\mathrm{C} 4$. Higher salivary aspartate aminotransferase levels seem to be related to periodontal destruction that includes periodontal pockets and gingival bleeding.
\end{abstract}

Key Words: Aspartate aminotransferase, Community periodontal index of treatment needs code, gingivitis, periodontitis, saliva.

\section{Introduction}

Periodontitis, a bacterially induced chronic inflammatory disease, destroys connective tissue \& bone that support the teeth [1]. As a consequence, breakdown of products are released into periodontal tissues, migrating toward the gingival sulcus and gathering from the surrounding site in whole saliva, where several of them have been identified namely, alkaline phosphatase, aspartate aminotransferase, glucuronidase, aminopeptidase enzymes, $\operatorname{IgA}$ and steroid hormones [2]. A reliable biochemical marker of tissue destruction would be desirable as an adjunct to currently available diagnostic methods. Commonly used clinical parameters or evaluations from radiographs can describe the history of periodontal disease, but these are not adequate diagnostic indicators of present or future periodontal deterioration [2]. The enzyme aspartate aminotransferase (AST) is one candidate for such a marker, suggested by its successful use as a diagnostic adjunct in human cardiac and hepatic tissue necrosis. AST also called Serum Glutamic Oxaloacetic Transaminase (SGOT). Following tissue damage, AST is released from injured and dead cells into extracellular fluid and can be readily assayed in serum, tears, gingival crevicular fliud, and saliva. AST activity has been extensively studied in both animal and human models. Although some research work is in progress, the relationship between salivary levels of AST activity and periodontal disease is not very clear as yet. So in this context we conducted a Clinico-biochemical study to assess the possible relation between salivary AST and stage of periodontal disease among the patients attending the department of Periodontics, as a salivary analysis can offer a cost-effective and non-invasive approach to monitor the progression of periodontal disease. The purpose of this study was to evaluate and compare the levels of AST in saliva in different periodontal conditions like healthy periodontium, gingivitis and periodontitis.

\section{Materials and Methods}

A total of 100 subjects, age ranging within 15-54 years were selected from the Outpatient Department of Periodontics P.M.N.M Dental College, Bagalkot. The subjects were selected randomly and segregated in four groups $(\mathrm{C} 0, \mathrm{C} 1, \mathrm{C} 3 \& \mathrm{C} 4)$ with 25 subjects each based on their largest community periodontal index of treatment needs (CPITN) score.

\subsection{CPITN scores}

Code 0 - No periodontal disease (Healthy periodontium)

Code 1 - Bleeding observed during or after probing

Code 2 - Calculus or plaque retentive factors either seen or felt during probing 
Code 3 - Pathological pocket 4-5mm in depth, gingival margin situated on black band of the probe

Code 4 - Pathological pocket $6 \mathrm{~mm} /$ more in depth, black band of the probe not visible

An ethical approval was obtained from PMNM Dental College \& Hospital Review Board Bagalkot, India. All the participants were explained regarding the procedure $\&$ an informed consent was obtained from them before the start of the study. Oral examination was performed using WHO probe and based on the clinical findings CPITN code was assigned to the specific group. Individuals presenting systemic diseases, pregnancy or who had taken antibiotics for any reasons within 3 months were excluded from the study. Code 2 classification was not included in the study because it evaluates only the presence or absence of supra \& subgingival calculus $\&$ is not necessarily associated with the tissue destruction.

About $1 \mathrm{ml}$ of non-stimulated whole saliva was collected in a sterile test tube from individuals immediately after a single mouth rinse with $15 \mathrm{ml}$ of water to wash out exfoliated cells and transferred to the laboratory for biochemical analysis to quantify the AST enzyme level, by IFCC (International Federation of Clinical Chemistry) method using Erba Mannheim kit (Transasia Bio-Medicals LTD. INDIA). This system or method was originally designed for the quantitative determination of clinical chemical parameters from whole blood, serum or plasma $\&$ is now being tested for saliva. This system provides the exact concentration of the enzyme in units per mililitre $(\mathrm{U} / \mathrm{ml})$.

\title{
2.2 IFCC methodology [3]
}

\author{
L-Aspartate + 2- Oxoglutarate $\stackrel{\text { AST }}{\longrightarrow}$ Oxaloacetate + L-Glutamate \\ Oxaloacetate + NADH $\stackrel{\mathrm{MDH}}{\longrightarrow}$ Malate + NAD \\ Sample pyruvate $+\mathrm{NADH} \underset{\mathrm{LDH}}{\longrightarrow}$ L-Lactate $+\mathrm{NAD}$ \\ AST: Aspartate aminotransferase, \\ LDH: Lactate dehydrogenase \\ MDH: Malate dehydrogenase
}

The reagents used in estimation of salivary AST levels are listed in Table 1.

According to the IFCC expert panel on enzymes, AST is stable for 3 days at $4^{\circ} \mathrm{C}$.

Allow the working reagent $(1000 \mu \mathrm{l})$ to attain $37^{\circ} \mathrm{C}$ before performing the test $(100 \mu \mathrm{l})$. Mix well and aspirate then place it in auto analyzer. Auto analyzer is a unit that performs the measurement of absorption, calculations, display or printing of the results automatically.

\section{Statistical Analysis}

Data are presented as mean, standard deviation (SD). Chi square test has been used to find the significant association of study parameters between the groups. Pairwise comparison was done by using Student's unpaired t-test.

\section{Results}

Mean levels of AST (U/ml) for groups C0 - 25.75, C1 - 30.59, C3 - 46.90 and C4 -100.28 (Table 2) and there were statistically significant differences $(\mathrm{p}<0.05$ ) between levels from group $\mathrm{C} 0$ to $\mathrm{C} 1, \mathrm{C} 3$ and $\mathrm{C} 4$. Higher salivary AST levels seem to be related to periodontal destruction that includes periodontal pockets and gingival bleeding. A comparison made between AST levels and CPITN groups using Chi-square test (Table 3). Fourteen (56\%) subjects under C0 group showed 15-24 U/ml AST level, 16 (64\%) subjects under $\mathrm{C} 1$ group showed 25$34 \mathrm{U} / \mathrm{ml}$ AST level and under C3 group, 8 (32\%) subjects showed $45-54 \mathrm{U} / \mathrm{ml}, 7$ subjects (28\%) showed 35-44 $\mathrm{U} / \mathrm{ml}$ and other 7 subjects (28\%) showed 55-64 U/ml AST level and under C4 group all 25 (100\%) subjects showed $>65 \mathrm{U} / \mathrm{ml}$ AST levels. This Chi-square test showed there was a statistically significant difference $(\mathrm{p}=$ 0.0000 ) between AST levels and CPITN groups. When comparison was made for gender and AST values (Table 4), showed statistically Non significant value ( $\mathrm{p}=0.9652)$.

\section{Discussion}

New diagnostic methods are needed that can detect disease-active periodontal sites and accurately predict those predetermined to become active. In medicine, clinical enzymology is used to aid in the diagnosis of localized inflammatory lesions prior to the development of overt clinical symptoms. The determination of AST levels in serum has been used for many years to identify inflammatory lesions in the heart, liver and kidney, and in cerebrospinal and synovial fluids for lesions in the brain and joints respectively [4]. This enzyme would be expected to pass from the periodontal tissues in the inflammatory exudates into the gingival crevicular fluid (GCF) and saliva. Deshpande and Kohad [5] observed remarkably higher levels of the AST enzyme in GCF than that in the blood. This rise in GCF enzyme level may be due to the cellular damage; predominantly PMNs at the diseased site, secondly the change in microbial flora at the diseased site may play a contributory role in determination of the enzyme activity. Smith et al. [6] have shown that GCF volume and enzyme activities differed among 6 sites sampled. Thus it is difficult to present values representative of a subject's oral cavity or even of one tooth. Contrary to the GCF, there is 
plenty of saliva, the procedure of its sampling is much easier and more bearable for the patient, and however, the same enzymes as those in the GCF can be detected. Because of the simple and non-invasive method of collection, salivary diagnostic tests appear to hold promise for the future. In a recent paper, Totan et al. [2] found a significant increase in salivary enzymatic activities in periodontitis patients, namely AST and alkaline phosphatase and alanine aminotransferase and emphasized their use in monitoring the periodontal disease. A few studies analyzed the levels of AST in GCF and saliva before and after periodontal treatment in periodontitis patients. Improvements in clinical status were noted following periodontal therapy and there was a corresponding decrease in AST levels. They concluded that AST levels may be a useful adjunct in the clinical assessment of periodontal disease, since AST level decreases when periodontal status improves [7,8]. Results of the present study showed increased mean levels of AST(U/ml) from C0 group (25.75) to C4 group (100.28), indicating the tendency of linear increase in the levels of AST activity reflects the advancing periodontal tissue injury and damage, which is in agreement with findings from few studies[5,9]. In the present study, association or comparison between AST levels and CPITN groups was done using Chi-square test (Table3). This test showed there was a statistically significant difference $(\mathrm{p}=0.0000)$ between AST levels and CPITN groups. 56\% of subjects under C0 group showed lowest AST levels $(15-24 \mathrm{U} / \mathrm{ml})$, this explains healthy patients have less AST levels compared to other groups. The increasing enzyme levels from group C0 to group C4 (100\% subjects showed highest; $>65 \mathrm{U} / \mathrm{ml})$, suggests that as the inflammatory condition develops the enzyme levels are increased, which further increase with tissue destruction. This finding is similar to the other reported studies $[9,10]$. The present study revealed, a higher levels of AST for group C1 (bleeding on probing) in comparison to healthy group $\mathrm{C} 0$. This observation made is consistent with the findings of Persson et al.[11] \& Emilio Silva et al.[12] who demonstrated that the occurrence of AST positive sites were associated with some amount of inflammation of gingival tissue, indicating a possible relationship between diseased sites and an inflammatory condition. Our results also showed AST levels in saliva from patients group C4 (pocket depth $\geq 6 \mathrm{~mm}$ ) were higher than from patients coded lower and is comparable with the previous studies $[2,8,9,12]$ showing high ratio of AST positive sites in deeper pockets.

The results of the present study indicate the positive correlation between the severity of periodontal condition and salivary enzyme activity of AST. The tendency of linear increase in the levels of AST activity reflects the advancing periodontal tissue injury and damage. Further a few reports coming forth suggesting the decrease of enzyme activity after periodontal therapy are encouraging to make us consider the AST level assessment as an adjunct to the other parameters in the management of periodontal diseases.

\section{Conclusion}

From this study, it could be concluded that salivary AST enzyme activity is increased in patients with periodontitis. A weak salivary immuno system makes the periodontal ligament more vulnerable to the destruction by enzymatically. Thus, this approach of biochemical analysis of salivary AST enzyme level is expected to facilitate the diagnosis of active periodontal disease and also in evaluating the response to the employed periodontal therapy. Further studies in this direction with larger study sample and especially longitudinal clinical studies involving the post periodontal therapy assessment of salivary enzymes in comparison to the pre treatment activity levels could prove of immense help in the management of periodontal diseases in the near future.

References

[1] Agnihotram G, Singh TR, Pamidimarri G, Jacob L, Rani S, Sravanthi. Study of clinical parameters in chronic periodontitis. Int.J.Appl.Biol.Pharm.Technol 2010; 1(3):1202-1208

[2]. Totan A, Greabu M, Totan C, Spinu T. Salivary aspartate aminotransferase, alanine aminotransferase, \& alkanine phosphatase. Possible markers in periodontal diseases? Clin Chem Lab Med 2006; 44:612-615.

[3]. Ladue.JS, Wroblewski F, Karmen. A. Serum glutamate oxaloacetate transaminase in human acute transmural myocardial infarction. Sci 1954; 120: 497-499.

[4]. Persson GR, Page RC. Diagnostic characteristics of crevicular fluid aspartate aminotransferase (AST) levels associated with periodontal disease activity. J Clin Periodontol 1992; 19: 43-48.

[5]. Deshpande BM, Kohad RM. Comparative study of alkaline phosphatase, aspartate transaminase and alanine transaminase in serum and gingival creivicular fluid in gingivitis and periodontitis. J Indian Soc Periodontol 1997; 21(3):71-73.

[6]. Smith AJ, Alexander M, Mackernzie D, Lennon A, Riggio MP, MacFarlane TW. Microbial factors and gingival crevicular fluid aspartate aminotransferase levels. A cross-sectional study. J Clin Periodontol 1998; 25: 334-339.

[7]. Todorovic T, Dozic I, Vicente-Barrero M, Ljuskovic B, Pejovic J, Marjanovic M et al. Salivary enzymes \& periodontal disease. Med Oral Patol Oral Cir Bucal 2006; Mar 1: 11(2): E115-9.

[8]. Shimada K, Mizuno T, Ohshio K, Kamaga M, Murai S, Ito K. Analysis of aspartate aminotransferase in gingival crevicular fluid assessed by using PocketWatchTM: a longitudinal study with initial therapy. J Clin Periodontol 2000; 27: 819-823.

[9]. Cesco R de T, Ito IY, Albuquerque RF Jr. Levels of aspartate aminotransferase (AST) in saliva of patients with different periodontal conditions. J Clin Periodontol 2003; 30: 752-755.

[10]. Richard JO, Howard HT, Marc LN, David SR, Gordon HD, Julio S et al. Relationship between crevicular aspartate aminotransferase levels and periodontal disease progression. J Periodontol 2001; 72:17-24.

[11]. Persson GR, De Roven TA, Pack RC. Relationship between levels of aspartate aminotransferase in gingival crevicular fluid and gingival inflammation. J Periodont Res 1990; 25:17-24. 
Comparative estimation of salivary aspartate aminotransferase levels in patients with varying

[12]. Barbosa e Silva E, Salvador SL, Fogo JC, Marcantonio RA. Use of aspartate aminotransferase in diagnosing periodontal disease: a comparative study of clinical and microbiological parameters. J Oral Sci 2003; 45: 33-38.

Table 1: Reagents

Table 2: Mean and SD of AST According to Four Groups

\begin{tabular}{|c|c|c|}
\hline \multicolumn{2}{|c|}{ 2-Oxoglutarate } & $12 \mathrm{mmol} / \mathrm{L}$ \\
\hline \multicolumn{2}{|c|}{ L-Aspartate } & $200 \mathrm{mmol} / \mathrm{L}$ \\
\hline \multicolumn{2}{|c|}{$\mathrm{MDH}$} & $\geq 545 \mathrm{U} / \mathrm{L}$ \\
\hline \multicolumn{2}{|c|}{ LDH } & $\geq 909 \mathrm{U} / \mathrm{L}$ \\
\hline \multicolumn{2}{|c|}{ NADH (Yeast) } & $\geq 0.18 \mathrm{mmol} / \mathrm{L}$ \\
\hline \multicolumn{2}{|c|}{ Tris Buffer $\left(\mathrm{pH}=7.8 \pm 0.1\right.$ at $\left.25^{\circ}\right)$} & $80 \mathrm{mmol} / \mathrm{L}$ \\
\hline \multicolumn{2}{|c|}{ EDTA } & $5.0 \mathrm{mmol} / \mathrm{L}$ \\
\hline Groups & Means & Standard Deviation \\
\hline $\mathrm{C} 0$ & 25.7480 & 7.6593 \\
\hline $\mathrm{C} 1$ & 30.5880 & 4.8893 \\
\hline $\mathrm{C} 3$ & 46.8960 & 10.9220 \\
\hline $\mathrm{C} 4$ & 100.2800 & 14.3413 \\
\hline Total & 50.8780 & 31.3454 \\
\hline
\end{tabular}

Table 3: Comparison/Association between AST Levels and CPITN Groups

\begin{tabular}{|c|c|c|c|c|c|}
\hline AST levels & $\mathrm{CO}$ & $\mathrm{C} 1$ & C3 & $\mathrm{C} 4$ & Totals \\
\hline $15-24$ & 14 & 3 & 0 & 0 & 17 \\
\hline $25-34$ & 7 & 16 & 3 & 0 & 26 \\
\hline $35-44$ & 4 & 6 & 7 & 0 & 17 \\
\hline $55-64$ & 0 & 0 & 7 & 0 & 7 \\
\hline $45-54$ & 0 & 0 & 8 & 0 & 8 \\
\hline $65+$ & 0 & 0 & 0 & 25 & 25 \\
\hline Totals & 25 & 25 & 25 & 25 & 100 \\
\hline
\end{tabular}

Table 4: Comparison of Male and Female With AST Values By Unpaired T-Test

\begin{tabular}{|c|c|c|c|c|c|c|}
\hline Gender & $\mathrm{n}$ & Mean & SD & t-value & p-value & Significant. \\
\cline { 1 - 4 } Male & 56 & 51.0000 & 31.4296 & 0.0437 & 0.9652 & NS \\
\hline Female & 44 & 50.7227 & 31.6005 & & & \\
\hline
\end{tabular}

